\title{
Incorporação de rocha sedimentar em pó em massas para telhas cerâmicas - Parte 2: avaliação microestrutural
}

\section{(Incorporation of sedimentary powder rock in roofing tiles body - Part 2: microstructural evaluation)}

\author{
C. M. F. Vieira, R. M. Pinheiro \\ Laboratório de Materiais Avançados - LAMAV, Universidade Estadual do Norte Fluminense Darcy \\ Ribeiro - UENF, Av. Alberto Lamego 2000, Campos dos Goytacazes, RJ, Brasil 28013-602 \\ vieira@uenf.br
}

\begin{abstract}
Resumo
Este trabalho teve por objetivo avaliar o efeito da incorporação de $50 \%$ em peso de argilito na microestrutura de uma cerâmica argilosa queimada a 950 e $1050{ }^{\circ} \mathrm{C}$. As amostras foram inicialmente selecionadas e lixadas a 1000 e 1200 mesh. A microestrutura das cerâmicas queimadas foi avaliada por microscopia eletrônica de varredura, microscopia óptica e difração de raios X. Os resultados mostraram que o argilito alterou a microestrutura da cerâmica, que acarretou um melhor desempenho técnico.
\end{abstract}

Palavras-chave: argilito, cerâmica vermelha, microestrutura.

\begin{abstract}
This work has as its objective to evaluate the effect of the incorporation of $50 \mathrm{wt} \%$ of argillite in the microstructure of a clayey ceramic fired at 950 and $1050^{\circ} \mathrm{C}$. Initially the specimens were selected and sanded to 1000 and 1200 mesh. The microstructure of the firing ceramic was evaluated by scanning electron microscopy, optical microscopy and $X$-ray diffraction. The results showed that the argillite changed the microstructure of the ceramic, generating a better technical performance.
\end{abstract}

Keywords: argillite, red ceramic, microstructure.

\section{INTRODUÇÃO}

O pólo cerâmico de Campos dos Goytacazes, norte do Estado do Rio de Janeiro, tem papel importante na economia local produzindo aproximadamente 200 milhões de peças/mês de cerâmica vermelha basicamente voltada para a produção de bloco de vedação [1]. A produção de cerâmicas de maior valor agregado como telhas, pisos rústicos e blocos estruturais é bem menor em comparação com os blocos de vedação. Uma das razões se deve à característica da matéria-prima disponível na região que possui comportamento refratário durante a etapa de queima que dificulta a obtenção de produtos com absorção de água dentro das especificações técnicas [1, 2]. Para resolver este problema devem-se utilizar temperaturas de queima mais elevadas e ainda reformular a composição de massa cerâmica utilizando materiais de baixa perda de massa durante a queima como inertes e fundentes. Alguns estudos recentes reportaram a adição de outros materiais para reduzir a porosidade após queima das massas utilizadas na produção de telhas da região [2,3]. A utilização de granito em pó, em até $30 \%$ em peso, elevou a densidade aparente a seco e reduziu a absorção de água de telhas cerâmicas queimadas a $970{ }^{\circ} \mathrm{C}$ em forno industrial. Entretanto, foi verificada uma queda na resistência à flexão atribuída à transformação alotrópica do quartzo que causou microtrincas nas cerâmicas [4]. Em outro estudo [5] os autores utilizaram uma rocha sedimentar em pó, argilito, para melhorar as propriedades tecnológicas das telhas produzidas na região. Foi observado que a incorporação de $30 \%$ de argilito a uma argila caulinítica de Campos dos Goytacazes melhorou significativamente a trabalhabilidade e as propriedades tecnológicas de queima, através da redução da porosidade nas temperaturas de 850 a $1050{ }^{\circ} \mathrm{C}$. Como conseqüência, ocorreu uma redução da absorção de água e aumento da resistência mecânica em comparação com a massa para telhas da região. Em baixas temperaturas, a redução da porosidade é mais fortemente influenciada pelo maior valor da densidade aparente a seco e menor perda de massa durante a queima das composições com argilito. Em temperaturas acima de $950{ }^{\circ} \mathrm{C}$, a formação de fase líquida possibilitou uma maior redução da porosidade, que é mais significativa com o incremento da quantidade de argilito incorporado. 
Tabela I - Composição química das matérias-primas (\% em peso) [5]. [Table I-Chemical composition of the raw materials (wt.\%) [5].]

\begin{tabular}{cccccccccc}
\hline & \multicolumn{10}{c}{ Composições } \\
\hline Matérias primas & $\mathrm{SiO}_{2}$ & $\mathrm{Al}_{2} \mathrm{O}_{3}$ & $\mathrm{Fe}_{2} \mathrm{O}_{3}$ & $\mathrm{TiO}_{2}$ & $\mathrm{CaO}$ & $\mathrm{MgO}$ & $\mathrm{K}_{2} \mathrm{O}$ & $\mathrm{Na}_{2} \mathrm{O}$ & $\mathrm{PF}$ \\
Massa Industrial & 51,58 & 23,37 & 8,72 & 1,22 & 0,34 & 0,89 & 2,06 & 0,59 & 10,85 \\
Argila Forte & 47,91 & 25,45 & 8,97 & 1,28 & 0,29 & 0,81 & 1,87 & 0,45 & 12,60 \\
Argilito & 56,02 & 17,70 & 9,04 & 1,05 & 1,11 & 4,09 & 5,77 & 0,21 & 4,80 \\
\hline
\end{tabular}

Tabela II- Composições estudadas (\% em peso).

[Table II - Studied compositions (wt.\%).]

\begin{tabular}{cccc}
\hline & Argila forte & Argila fraca & Argilito \\
\hline MI & 70 & 30 & - \\
AF50A & 50 & - & 50 \\
\hline
\end{tabular}

O presente trabalho objetivou dar continuidade ao estudo [5] por meio da avaliação da microestrutura das cerâmicas com aplicação das técnicas de difração de raios $\mathrm{X}$, microscopia eletrônica de varredura e microscopia ótica.

\section{MATERIAIS E MÉTODOS}

Foram utilizados os seguintes materiais: massa argilosa, empregada para fabricação de cerâmica vermelha, proveniente do município de Campos dos Goytacazes, RJ, formada por $70 \%$ argila plástica "forte" e por $30 \%$ argila menos plástica, "fraca", com maior teor de areia. O outro material foi argilito em forma de pó proveniente da região de Itu, SP, usado para fabricação de cerâmica estrutural. A Tabela I apresenta a composição química das matérias-primas estudadas. A massa industrial e a argila forte apresentam baixos teores de óxidos que atuam como fundentes e elevada perda ao fogo. Já o argilito apresenta maior teor de óxidos fundentes e menor perda ao fogo [5]. Com relação à composição mineralógica, o argilito é constituído de caulinita, mineral micáceo, hematita, quartzo e microclina. Esta composição mineralógica é bastante similar às argilas.

Foram investigadas duas composições, conforme indicado na Tabela II. A composição MI corresponde a uma massa industrial de telhas do município de Campos dos Goytacazes. Já a composição CARJ-1 corresponde a uma massa elaborada com uma argila de Campos dos Goytacazes, conhecida no jargão cerâmico como "forte" e $50 \%$ em peso de argilito, submetido à trituração industrial em moinho de martelos.

Corpos-de-prova retangulares nas dimensões de $108 \mathrm{x}$ $20 \times 15 \mathrm{~mm}^{3}$ foram conformados por extrusão em maromba de laboratório com teores variáveis de água de conformação, determinados por meio da consistência das massas. Em seguida, os corpos de prova foram secos a temperatura ambiente por $72 \mathrm{~h} \mathrm{e} \mathrm{em} \mathrm{estufa} \mathrm{a} 110^{\circ} \mathrm{C}$ até peso constante. A queima das cerâmicas foi realizada em forno de laboratório a 950 e $1050{ }^{\circ} \mathrm{C}$, com taxa de aquecimento de $3{ }^{\circ} \mathrm{C} / \mathrm{min}$ e $180 \mathrm{~min}$ de patamar. $\mathrm{O}$ resfriamento ocorreu naturalmente, desligando-se o forno [5]. As amostras foram selecionadas e lixadas em lixa de 1000 e 1200 mesh por 15 min em cada lixa para obter uma melhor visualização da superfície das cerâmicas. A microestrutura foi avaliada por microscopia ótica em microscópio Motic Agar-Scientific e por microscopia eletrônica de varredura em um microscópio SSX-550 Shimadzu SEDX. A investigação das fases formadas foi feita por difração de raios $\mathrm{X}$ em difratômetro XRD 7000 Shimadzu operando com radiação $\mathrm{Cu}-\mathrm{k}_{\alpha}$ e $2 \theta$ variando de 5 a $60^{\circ}$.

\section{RESULTADOS E DISCUSSÃO}

A Fig. 1 apresenta os difratogramas de raios $\mathrm{X}$ das cerâmicas MI e AF50A, que representa a composição com teor máximo de argilito incorporado, queimadas nas temperaturas de $950,1050{ }^{\circ} \mathrm{C}$. Observa-se nas Figs. 1a e $1 \mathrm{~b}$, cerâmicas queimadas na $950{ }^{\circ} \mathrm{C}$, três fases cristalinas: quartzo, mica e hematita. As duas primeiras fases são ditas residuais, ou seja, provenientes da matéria-prima no seu estado natural. Já a hematita é proveniente da desidratação de hidróxidos de ferro, eventualmente presentes nas argilas de Campos dos Goytacazes, RJ [2]. A $1050{ }^{\circ} \mathrm{C}$ a mica desaparece, ocorre diminuição na intensidade dos picos de quartzo e surge a fase mulita e de feldspatos potássicos como a sanidina e o ortoclásio. A mica desaparece devido à formação de fase líquida, a diminuição da intensidade dos picos de difração do quartzo, indica que se inicia sua dissolução na fase líquida formada. Já a mulita é uma fase de aluminosilicato proveniente da decomposição da metacaulinita.

A seguir são apresentadas micrografias, obtidas por microscopia óptica, da superfície dos corpos-de-prova correspondentes às composições MI e AF50A queimadas a 950 e $1050^{\circ} \mathrm{C}$. Foi possível observar com bastante clareza as partículas de quartzo dispersas na matriz de aluminosilicato além da presença de fases ricas em ferro na composição com argilito.

As Figs. 2 e 3 mostram as micrografias obtidas por microscopia óptica das cerâmicas queimadas a $950{ }^{\circ} \mathrm{C}$, MI e AF50A, respectivamente. Observa-se na Fig. 2 uma superfície com aspecto ligeiramente mais rugosa do que as cerâmicas apresentadas na Fig. 3. Esta rugosidade está associada à baixa consolidação das partículas. A $950^{\circ} \mathrm{C}$ os mecanismos de sinterização ainda não foram expressivos o suficiente para eliminar a porosidade provocando um alisamento da superfície da cerâmica característico em 

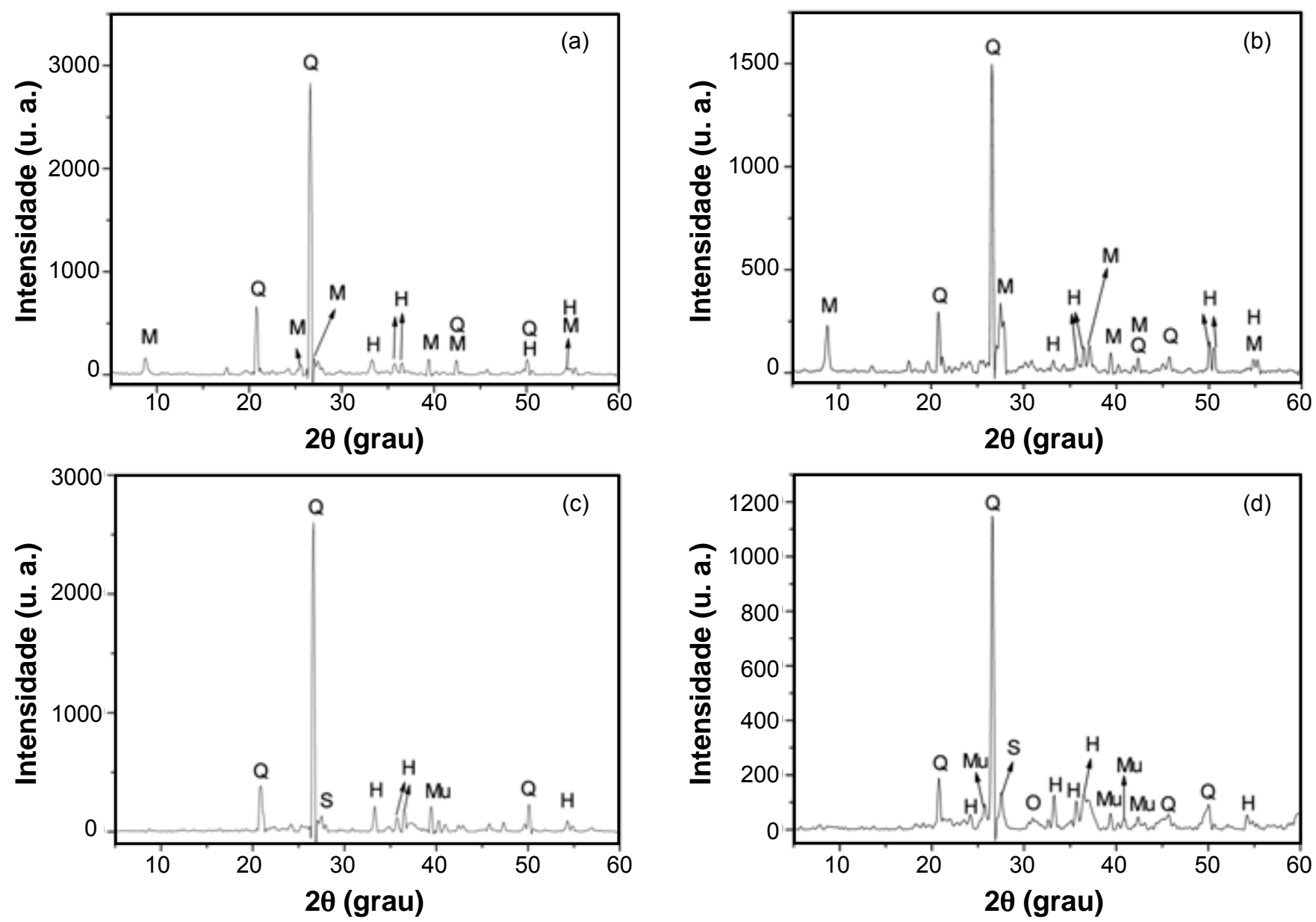

Figura 1: Difratogramas de raios $\mathrm{X}$ das cerâmicas queimadas. (a) $\mathrm{MI}$ a $950{ }^{\circ} \mathrm{C}$ e (b) $\mathrm{AF} 50 \mathrm{~A}$ a $950{ }^{\circ} \mathrm{C}$; (c) $\mathrm{MI}$ a $1050{ }^{\circ} \mathrm{C}$ e (d) $\mathrm{AF} 50 \mathrm{~A}$ a $1050^{\circ} \mathrm{C} . \mathrm{M}=$ mica muscovita; $\mathrm{Q}=$ quartzo; $\mathrm{Mu}=$ mulita; $\mathrm{H}=$ hematita; $\mathrm{S}=$ sanidina; $\mathrm{O}=$ ortoclásio.

[Figure 1: X-ray diffraction patterns of the fired ceramics. (a) MI at $950{ }^{\circ} \mathrm{C}$ and (b) $\mathrm{AF50A}$ at $950{ }^{\circ} \mathrm{C}$; (c) $\mathrm{MI}$ at $1050{ }^{\circ} \mathrm{C}$ and (d) $\mathrm{AF} 50 \mathrm{~A}$ at $1050^{\circ} \mathrm{C}$. $M=$ muscovite mica; $Q=$ quartz; $M u=$ mullite; $H=$ hematite; $S=$ sanidine; $O=$ ortoclase.]
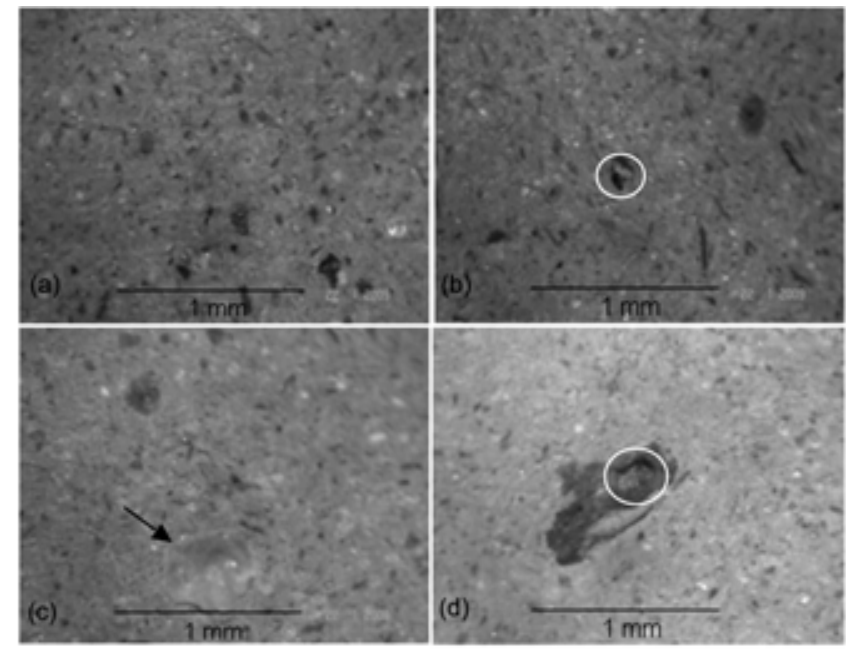

Figura 2: Micrografias obtidas por microscopia óptica da cerâmica MI queimada a $950{ }^{\circ} \mathrm{C}$.

[Figure 2: Optical microscopy micrographs of the ceramic MI fired at $\left.950^{\circ} \mathrm{C}.\right]$

temperaturas elevadas. Observa-se na Fig. 2c, indicada pela seta preta, uma partícula de quartzo com tamanho

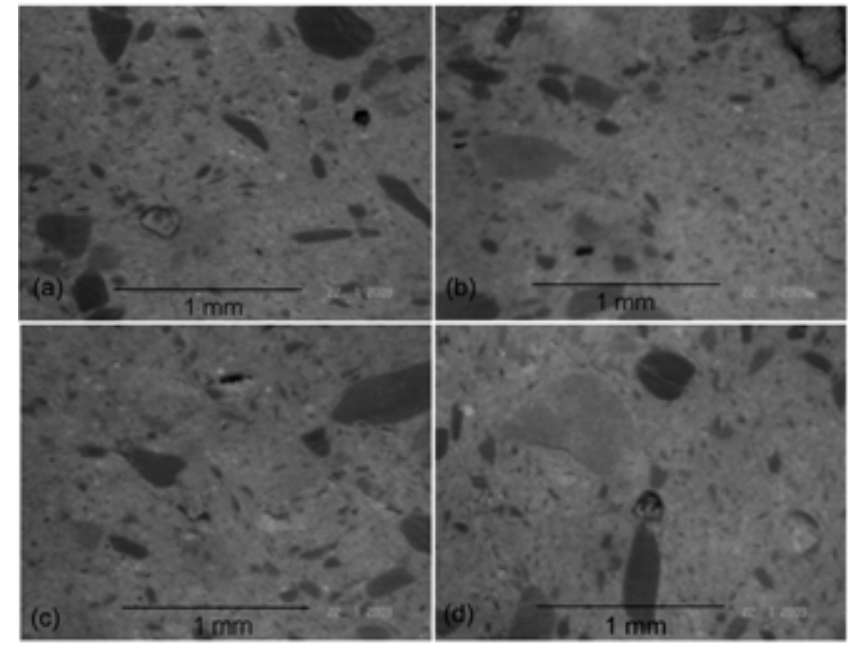

Figura 3: Micrografias obtidas por microscopia óptica da cerâmica AF50A queimada a $950{ }^{\circ} \mathrm{C}$.

[Figure 3: Optical microscopy micrographs of the ceramic AF50A fired at $950^{\circ} \mathrm{C}$.]

aproximado de $0,5 \mathrm{~mm}$. São observados também nas Figs. $2 \mathrm{~b}$ e $2 \mathrm{~d}$ círculos brancos, poros na superfície da cerâmica 


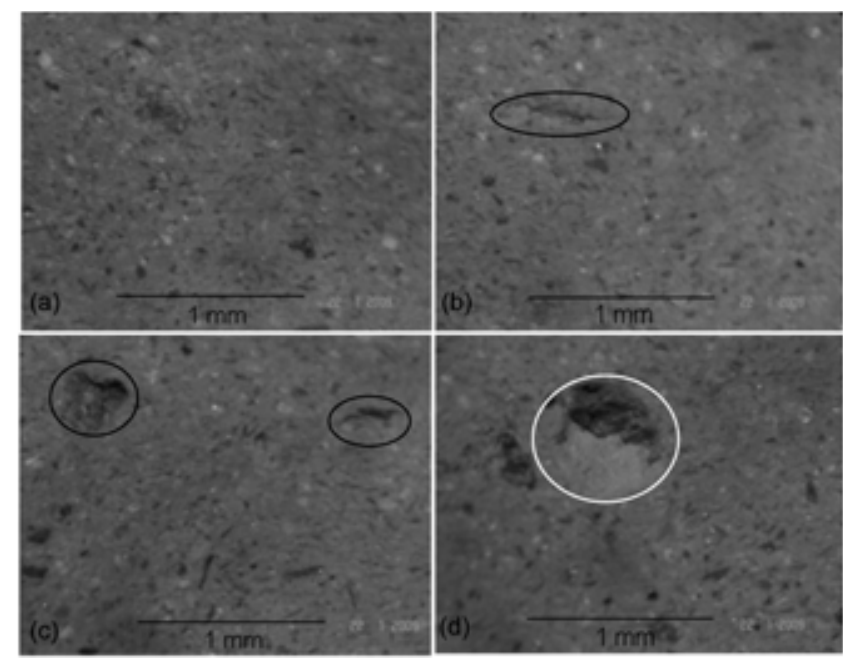

Figura 4: Micrografias obtidas por microscopia óptica da cerâmica MI queimada a $1050^{\circ} \mathrm{C}$.

[Figure 4: Optical microscopy micrographs of the ceramic MI fired at $1050^{\circ} \mathrm{C} .7$
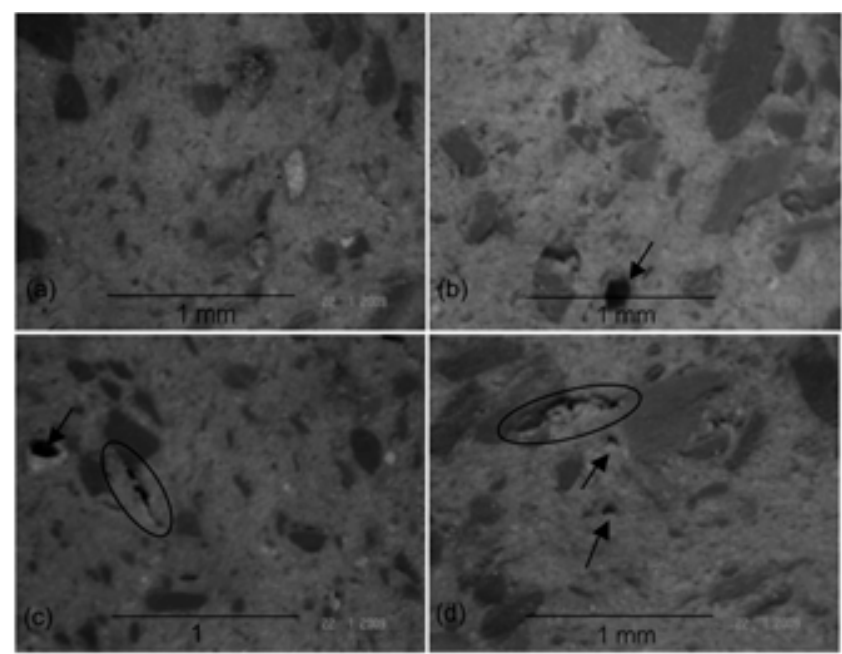

Figura 5: Micrografias obtidas por microscopia óptica da cerâmica AF50A queimada a $1050{ }^{\circ} \mathrm{C}$.

[Figure 5: Optical microscopy micrographs of the ceramic AF50A fired at $1050^{\circ} \mathrm{C}$.]
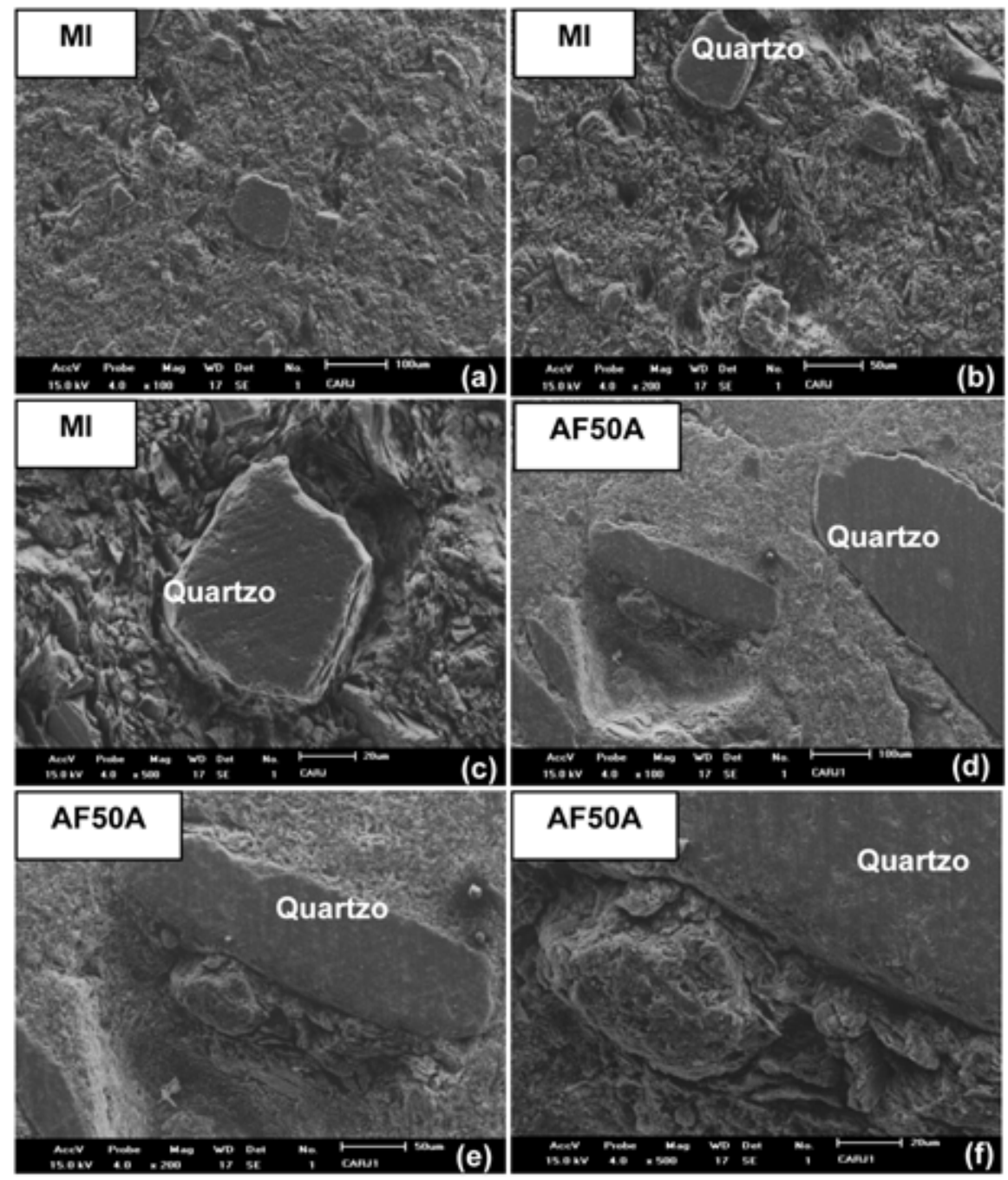

Figura 6: Micrografias obtidas por microscopia eletrônica de varredura das cerâmicas MI, (a), (b) e (c) e AF50A, (d), (e) e (f), queimadas a $950{ }^{\circ} \mathrm{C}$.

[Figure 6: SEM micrographs of the ceramics MI, (a), (b) and (c) and AF50A, (d), (e) and (f), fired at 950 ${ }^{\circ} \mathrm{C}$.] 
inerente ao processamento cerâmico.

AFig. 3 apresenta uma superfície um pouco mais uniforme com aspecto mais liso do que na Fig. 2. Isto ocorre devido à presença de argilito na composição de massa. Embora 950 ${ }^{\circ} \mathrm{C}$ não seja capaz de sinterizar eficientemente a cerâmica, a presença de materiais fundentes e inertes no argilito associada sua baixa perda de massa, contribuíram para um menor nível de porosidade. Possivelmente, a hematita atue como uma fase inerte e inibidora de propagação de trincas. A vantagem da hematita em relação ao quartzo é a ausência de variação volumétrica devido à transformação alotrópica [6].

As Figs. 4 e 5 mostram as micrografias obtidas por microscopia óptica das cerâmicas MI e AF50A, respectivamente, queimadas a $1050^{\circ} \mathrm{C}$. Nesta temperatura é possível observar uma superfície mais compacta com menos rugosidade do que a $950^{\circ} \mathrm{C}$. Entretanto, é possível observar nas Figs. 4b, 4c e 4d defeitos como trincas e poros. Na Fig. $4 \mathrm{~d}$, circulado em branco, nota-se uma falha, ausência de material, com tamanho aproximado de $0,6 \mathrm{~mm}$.
Na Fig. 5 notam-se além de poros, indicados por setas, e trincas, circundadas, fases avermelhadas dispersas na matriz. Estas fases possivelmente estão associadas à hematita, fase presente conforme indicado na Fig. 1.

A Fig. 6 mostra as micrografias obtidas por microscopia eletrônica de varredura da superfície das cerâmicas queimadas a $950{ }^{\circ} \mathrm{C}$, MI e AF50A, respectivamente, com aumentos de 100, 200 e 500x. A microscopia eletrônica de varredura permite observar, com muito mais clareza que a microscopia ótica, a rugosidade das cerâmicas, evidenciando também os defeitos. Um fator comum para ambas as cerâmicas é a presença de partículas de quartzo. O quartzo é um mineral comumente presente nas argilas. Embora o quartzo tenha efeito benéfico para o processamento da cerâmica, geralmente ocorre também um comprometimento da resistência mecânica devido à sua transformação alotrópica a $\sim 573{ }^{\circ} \mathrm{C}[6]$. A variação de volume que ocorre acarreta o aparecimento de defeitos na cerâmica, conforme evidenciado nas micrografias abaixo.
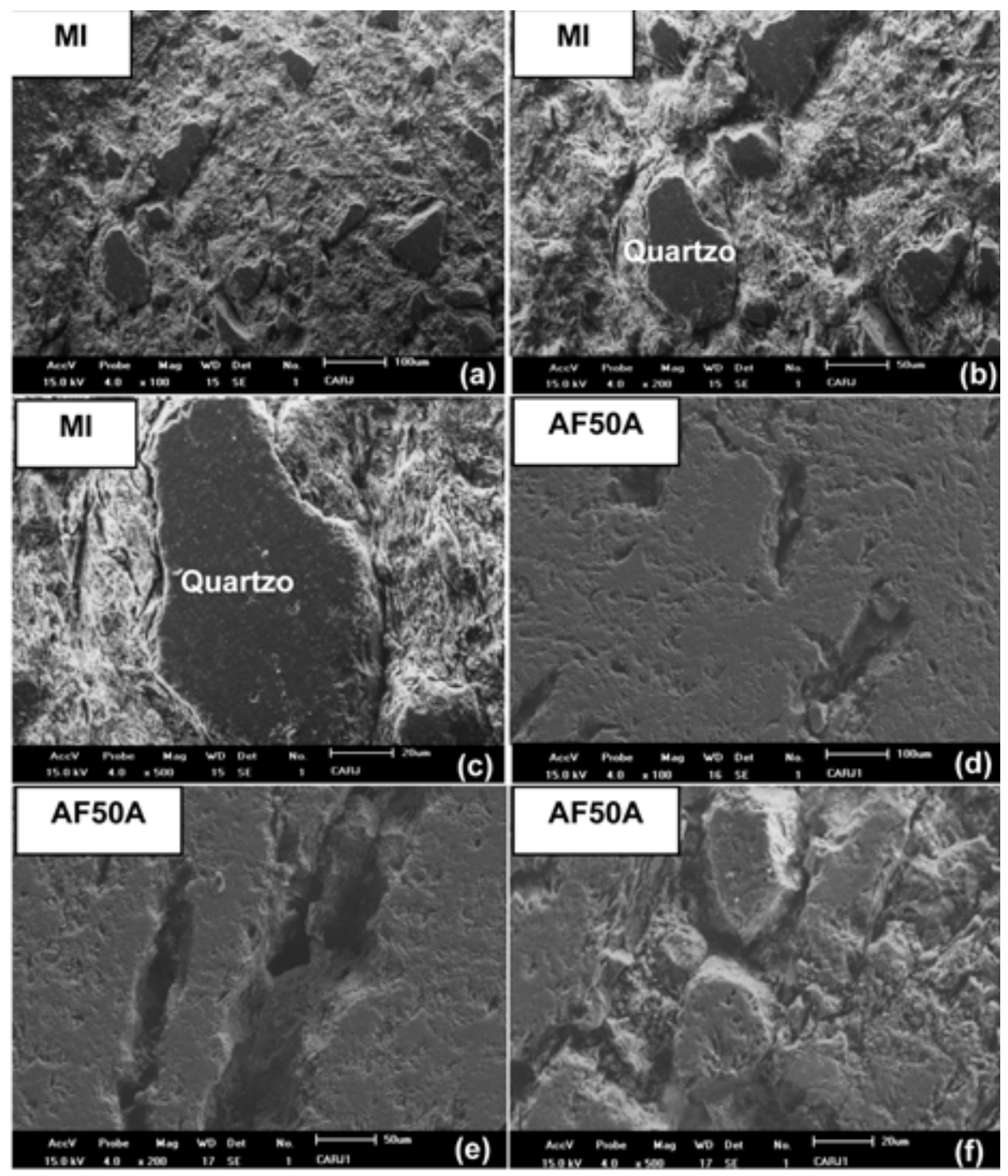

Figura 7: Micrografias obtidas por microscopia eletrônica de varredura das cerâmicas MI, (a), (b) e (c) e AF50A, (d), (e) e (f), queimadas a $1050{ }^{\circ} \mathrm{C}$.

[Figure 7: SEM micrographs of the ceramics MI, (a), (b) and (c) and AF50A, (d), (e) and (f), fired at $1050^{\circ} \mathrm{C}$.] 
Na Fig. 7 são apresentadas as micrografias das cerâmicas MI, Figs. 7a, 7b e 7c, e AF50A, Figs. 7d, 7e e 7f, queimadas a $1050{ }^{\circ} \mathrm{C}$ respectivamente, com aumentos de $100,200 \mathrm{e}$ $500 x$. Nesta temperatura, embora ainda seja possível notar defeitos microestruturais, a consolidação das partículas é mais evidente, Fig. 7d. Consequentemente, as propriedades físicas e mecânicas das cerâmicas apresentam uma melhora significativa. Foi observado um aumento de $50 \%$ na resistência mecânica da cerâmica MI queimada a $1050{ }^{\circ} \mathrm{C}$ em comparação com a queimada a $950{ }^{\circ} \mathrm{C}$. Para a cerâmica AF50A este aumento foi de $107 \%$ [5].

\section{CONCLUSÕES}

A incorporação de argilito promoveu melhorias na microestrutura da cerâmica argilosa, com diminuição significativa da porosidade e, como conseqüência, proporcionado redução na absorção de água. Com o aumento da temperatura de queima observou-se uma microestrutura mais compacta e densa e consequentemente menos porosa para ambas as cerâmicas investigadas. Foi observado que o argilito proporcionou um aumento da hematita nas fases de queima. Isto, além de alterar a coloração pôde ter contribuído para melhorar a resistência mecânica da cerâmica. De um modo geral, foi observado que o argilito melhorou significativamente a microestrutura da cerâmica. Entretanto, a distância que se encontra disponível tal matéria-prima, pode ser um entrave para sua utilização na região de Campos dos Goytacazes, RJ. É necessário um estudo de viabilidade econômica.

\section{AGRADECIMENTOS}

À FAPERJ (Proc. E-26/111.166/2011) e ao CNPq (Proc. 301778/2011-6).

\section{REFERÊNCIAS}

[1] S. N. Monteiro, C. M. F. Vieira, Tile Brick Int. 18 (2002) 152-157.

[2] S. N. Monteiro, C. M. F. Vieira, App. Clay Sci. 27 (2004) 229-234.

[3] C. M. F. Vieira, H. F. Sales, S. N. Monteiro, Cerâmica 50, 315 (2004) 239-246.

[4] C. M. F. Vieira, T. M. Soares, S. N. Monteiro, Cerâmica Industrial 9 (2004) 36-40.

[5] C. M. F. Vieira, J. V. Emiliano, Cerâmica 59, 351 (2013) 389-394.

[6] E. Facincani, Tecnologia Cerâmica - los Ladrillos, Faenza Editrice Iberica S. L. Editora, Barcelona, Espanha (1993) 263.

(Rec. 23/05/2012, Rev. 27/08/2012, Ac. 28/12/2012) 